\title{
THE CATEGORICAL IMPERATIVE AND KANT'S CONCEPTION OF PRACTICAL RATIONALITY
}

\section{Introduction}

The primary concern of this paper is to outline an explanation of how Kant derives morality from reason. We all know that Kant thought that morality comprises a set of demands that are unconditionally and universally valid (valid for all rational beings). In addition, he thought that to support this understanding of moral principles, one must show that they originate in reason $a$ priori, rather than in contingent facts about human psychology, or the circumstances of human life. ${ }^{1}$ But do we really understand how he tries to establish that moral principles originate in reason? In at least two passages in the second section of the Groundwork, Kant insists upon the importance of grounding the moral law in practical reason $a$ priori, and subsequently states a conception of practical reason from which he appears to extract a formulation of the Categorical Imperative. ${ }^{2}$ The reasoning employed in these passages would appear to be of central importance to the overall argument of the Groundwork, but in each case the route travelled from the definition of practical reason to the ensuing formulation of the moral law is obscure. My goal is to work out a plausible reconstruction of this portion of Kant's argument. At the very least, I hope that my interpretation will illuminate the distinctive structure of the Kantian approach to questions of justification in ethics. What I understand of Kant's view leads me to believe that its aims and overall shape are different in important respects from what is often assumed. It also represents an approach to foundational issues in ethics, which provides an alternative to many contemporary attempts to ground morality in reason.

I will be limiting myself to a small part of this very large question. Theories of this sort, Kant's included, tend to address two separate questions of justification. The first is that of justifying one substantive moral conception as opposed to another. This is primarily a concern with content: which moral principles should we adopt, given the fact that we are going to adopt some? The second is that of giving some account of why moral reasons make valid claims on agents, or why we should adhere to them (whatever they may involve). This is a concern with the reasons that one has for acting morally, or with the justification of the moral life. In part this is a question 
of identifying, or producing, the motivation for adhering to moral principles, but I shall refer to it less specifically as a concern with their validity. I will be examining Kant's approach to the first issue-how he derives the outline of a substantive moral conception from a concept of practical reason. ${ }^{3}$ Here I shall be particularly concerned to identify the conception of practical rationality that Kant draws on, and to explain how it functions in his derivation of morality.

Contemporary attempts to derive morality from reason often seek an independent foundation for morality in a more basic conception of rationality. As David Wiggins has put it, such a theory supposes that one can "construct an a priori theory of rationality or prudence such that . . . rationality is definable both independently of morality and ideals of agency and in such a way as to have independent leverage in these ancient disputes." 4 In other words, it seeks a comprehensive and morally neutral definition of practical rationality that is universally valid, from which a set of moral principles can be derived. In this way, one would have provided a justification for a set of moral principles, and shown that adherence to them is a basic requirement of rationality on conduct, which has authority for any agent regardless of professed desires and motives.

It is often assumed that Kant's theory fits this pattern, by attempting to provide a foundation for morality that is morally neutral, and thus, in Bernard Williams's phrase, to construct morality "from the ground up."'s I will argue that this is not the case. While the conception of practical rationality which Kant assumes is $a$ priori and has a claim to universal validity, it is not empty of substantive ideals. Indeed it is a distinguishing feature of a Kantian view that it does not attempt to derive morality from a morally neutral starting point. Its general structure is that it ties the content of a moral conception to a more general set of ideals-of the person, of agency, or of rationality-which, while applying widely, and providing some kind of independent perspective on morality, need not be empty of moral content. The validity of the moral conception for us is established by the fundamental character of these ideals and the reasonableness of applying them to ourselves, and the motivation to act from it comes ultimately from an understanding of the ideals in question, and of how they are expressed in the actions which it singles out.

If this is the case, Kant's account is not aimed at showing that bad conduct is irrational, or inconsistent with principles to which one is committed qua rational, as that is often understood, where the sense of irrationality is explained solely in terms of prudential or instrumental rationality plus 
logical consistency. More generally, Kant clearly did not think that any form of instrumental rationalty (rationality as the effective pursuit of one's ends, or as consistency among desires, beliefs and actions) is sufficient by itself to yield a moral conception. For it is fundamental to his moral view that we recognize different forms of practical reasoning, that moral evaluation is distinct from prudential and involves a set of concerns not reducible to something more primitive. ${ }^{6}$ The Hypothetical Imperative and the Categorical Imperative, or what Kant also calls empirical practical reason and pure practical reason, represent different kinds of normative standards and patterns of evaluation. Indeed it is a major aim of the Critique of Practical Reason to show that the "empirically conditioned use of reason" does not exhaust the use of reason in the practical sphere, and that there is such a thing as pure practical reason. [ $K p V 15 / 15]$

We may distinguish these two forms of rationality provisionally as follows. The Hypothetical Imperative is the principle underlying the empirically conditioned use of reason. It states that if one wills an end, then one ought to will the means needed to achieve it insofar as they are in one's power (or else give up the end). It assesses the rationality of actions relative to the ends which one desires or has adopted, and thus yields specific judgments about what an individual ought to do only in conjunction with information about her ends. ${ }^{7}$ What makes this use of reason "empirically conditioned" is that it assesses actions relative to given desires or ends, and yields judgments whose application is conditional on one's desires or ends. The Hypothetical Imperative is often thought to apply primarily to the pursuit of one's own happiness, but in fact it applies to the pursuit of any end that an agent can adopt, including moral ends. In contrast, pure practical reason will address questions of evaluation that are beyond the scope of empirical practical reason. It will introduce standards for evaluating actions and ends that are non-instrumental, and apply independently of given desires and ends-principles which ground judgments of intrinsic goodness or acceptability to anyone, which for Kant are the basis of justification to others. There are grounds for thinking, in addition, that pure practical reason will be concerned with the evaluation and choice of ends for their own sake (in contrast to the choice of actions as means to ends). This will include the capacity to elect aims and goals viewed as intrinsically good or worthy of choice, which can initiate actions and structure larger practical pursuits. ${ }^{8}$

Any account of how Kant derives the content of the moral law from reason must be consistent with the existence of these distinct forms of rationality. But then the question arises of how a derivation of the moral law 
from reason can actually be carried out. The moral law cannot be derived from any notion of empirical practical reason, and a derivation from pure practical reason would seem to lack independent force, since it already contains the concerns essential to morality. In a sense this is right. On the interpretation that I develop, something like moral ideals are embedded in the conception of choice and the ordinary use of practical reason from the start. But the way to explain Kant's view is to show how moral choice builds on features present in any form of choice, and thus to trace morality to features of rationality found in all forms of conduct. The fact that moral rationality cannot be derived from a more primitive (non-moral) basis need not imply that it is not found in less developed forms.

The key here is that Kant thought that both forms of reasoning inform all rational choice, including choice of actions that we might not think of as morally motivated. Even in the pursuit of purely personal ends, the rational agent is not concerned solely to make her actions rational relative to her desires. She will also view at least some of her ends as good in themselves, and as providing reasons for her actions whose justifying force extends to the point of view of others. Thus the concern with justifying reasons and with the goodness of ends that define pure practical reason is found, in some form, in all choice; indeed, comprises the essential element in choice.

If moral reasoning represents a distinct form of rationality found in all forms of choice, then Kant's derivation of the moral law from reason should be understood along the following lines: moral choice represents the most complete realization of an ideal of rationality found in all forms of choice. All choice meets certain conditions, which, in moral choice, are extended to their limit, or completed-so that the conditions that define moral choice are built into the ordinary notion of rational choice.

To explain: we think of choice as guided by reasons, or normative considerations that the agent takes to provide some justification for an action. The reasons that guide agents' choices lead them to view their actions as good in some respect (and this is the source of their motivating force). They also have normative force from the point of view of others. They may be cited to explain or justify an action to others; and even if such explanations do not get others to accept or approve, they may provide a partial justification by enabling others to see why the agent took the action to be a good thing to do. In addition, Kant assumes, not implausibly, that as rational agents we take some of our reasons to be final or ultimate. The particular reasons for action that we may cite are in turn supported by more general reasons or principles, which give the particular reasons their normative force. Thus it would appear to be a structural feature of practical reason 
that some reasons function as final or ultimate reasons: they are viewed (by an agent) as good per se, and as conferring support on more specific concerns from which we act. What different agents take to provide final reasons may be quite varied. They could include specific ends or activities, such as a successful career, a personal relationship, or involvement in a social cause; or more general aims-e.g., happiness, or leading an honorable life. They might also be values such as honesty, fairness, or protecting one's own interests. Furthermore, an agent's final reasons may be more or less admirable. Some, properly cited, may be sufficient to get others to accept or approve of the resulting actions; others may fall short of this, rendering an action intelligible without fully justifying it.

This characterization of rational choice allows us to see the way in which moral choice might be viewed as the most complete realization of an ideal of rationality found in all forms of choice. Morally good choices are those which are fully justified in that the agent acts from reasons which are final and universally valid. What happens in moral choice is that the normative force characteristic of any reason has been extended along certain dimensions, as it were. In particular the justifying force which they have for the agent is universal and extends to the point of view of any agent-so that it is sufficient to lead anyone to accept the action as good. In short, all rational choice is guided by normative considerations (reasons with normative force for the agent). In moral choice, the reasons from which the agent acts are in fact sufficient to justify the action to anyone.

I will now argue that such a view underlies Kant's derivation of the Categorical Imperative, and offers the best understanding of the connection that he draws between moral principles and the nature of practical reason. To do so I will offer a reconstruction of the derivation of the Formula of Universal Law in the first two sections of the Groundwork. Section 2 of the paper is an overview of the argument of Groundwork, I, which explains how Kant thinks that the concept of morality implicit in ordinary thought leads to the Formula of Universal Law. Sections 3 through 5 explain, respectively, what leads Kant to undertake another derivation of the Formula of Universal Law in Groundwork, II-this time one that traces it to the nature of practical reason; his conception of practical reason; and how it is most fully expressed by the Categorical Imperative.

\section{The Aims of Groundwork, I}

The Groundwork offers a foundational account of a concept of morality that Kant takes to be well-established in ordinary thought and practice; indeed he takes it to be the concept of morality. His concern is to 
provide an account that preserves and grounds its essential features. The initial aim of the First Section is to articulate the defining features of this concept of morality through an examination of ordinary moral consciousness-that is, through examples and attention to our concept of a "duty." What has received most attention are Kant's theses about moral worth-that an action has moral worth when done from the motive of duty, and that its moral worth is determined by its underlying principle, rather than its results or intended consequences. ${ }^{9}$ While important Kantian doctrines, they ought to be viewed as intermediate conclusions on the way to the larger objective of a formulation of the Categorical Imperative. Kant uses his discussion of when an action displays a good will (has moral worth) to get at the principle of right conduct which a good will uses in assessing actions and deciding how to act. [Gl 392, 403-404] $]^{10}$

I would argue that Kant's examination of ordinary moral consciousness in Groundwork, I, produces two results of primary importance. First, it reveals the special authority that (it is part of our concept of morality that) moral reasons and value have in practical deliberation. In more general terms, it reveals the formal features of moral reasons which are definitive of our concept of morality-the necessity and univerality with which they are thought to apply. Second, from this concept of morality Kant derives the moral principle implicit in ordinary thought. He attempts to move from the formal features of moral reasons to the principle that allows us to determine what moral reasons there are in a given situation. This principle will turn out to be a representation of the general form of reasoning implicit in actual instances of moral deliberation. ${ }^{11}$ The movement of the argument here is from form towards content, or more accurately, from formal considerations to a principle that, with suitable input, may be used to construct a substantive moral conception. Argumentation of this sort is characteristic of Kant's moral theory, and this same move is repeated in Groundwork, II. Here Kant argues that the very concept of a categorical imperative provides the only principle that can be a categorical imperative. An imperative that commands categorically (whatever its content) specifies an action as unconditionally and absolutely good, and thus applies with the necessity of a practical law. ${ }^{12}$ Kant thinks that these concepts lead to the Formula of Universal Law, as a principle that expresses the concept of a practical law, or states the form of an unconditional requirement on action. Ultimately Kant will argue that the "form of volition in general" yields a principle by which one may guide one's particular volitions and choices. [Cf. $G l$ 444.] Here we see an important aspect of his claim that morality must rest on the principle of autonomy: the very nature of the will yields the principle from which the standards we recognize as moral are derived. 
In the text, the notion of respect for the moral law provides the bridge between the claims about moral worth and the statement of the moral law, by focussing our attention on the overriding authority that moral concerns have in our thought. ${ }^{13}$ Kant's examples have shown that the agent who exhibits the exemplary moral attitude is motivated simply by the recognition that his action is right-that is, by respect for the moral law. The motive of respect "excludes the influence of inclination," but also "outweighs it." $[G l 400,401]$ It is a response to a kind of intrinsic value that is not mediated by an agent's desires. But more importantly, it is the recognition of a value that overrides other forms of value. To show respect for the moral law is to give the reasons which it yields an absolute weight in practical deliberation. [ $G l 401 \mathrm{n}, 403$ ] In this way, the attitude of respect for the law shows us that we take moral reasons to apply with necessity (do not presuppose any particular desires on the part of the agent and are independent of ways in which individuals tend to act) and to have absolute priority over other kinds of reasons (i.e., are overriding relative to the reasons given by an agent's desires). Their application must also be universally valid, since it is independent of contingent features of the self and motives an agent could lack. ${ }^{14}$ They represent reasons that would hold for anyone in the relevant situation, and reasons that anyone can recognize as valid and authoritative. Necessity, absolute priority and universal validity are formal features in that they can be attributed to moral reasons without specifying the particular actions which such reasons pick out, and they may be taken as definitive of morality. ${ }^{15}$ It is simply part of our concept of morality that, whatever moral reasons there turn out to be, they will apply to us in this way.

Otherwise put, reflection on the attitude of respect shows that we take moral principles and reasons to have the status of law. As the recognition of an order of value that limits the authority of other forms of value, respect is the proper attitude towards a law as such. Thus it shows that the idea of a practical law is central to our concept of morality. Here it is important to note that a practical law is not just a principle which makes claims about how anyone should act in a kind of situation, or one whose validity anyone can recognize-i.e., one which is universal in form. A practical law, in addition, provides reasons of special weight. Its application to an agent's circumstances yields determinate reasons for acting that apply with necessity and take priority over other kinds of reasons. ${ }^{16}$ By noting how the conditions of necessity and universality function together, we can see that a practical law also grounds a kind of justification, which will be equally central to our concept of morality. The absolute weight that moral reasons possess must itself be one of the features that is universally applicable. Thus, the application of a practical law yields reasons for acting that anyone can 
recognize as overriding in that situation. That would seem to be the strongest kind of reason that there is, and one which justifies completely.

This suggests a way of understanding Kant's final move to the statement of the Formula of Universal Law in Groundwork, I. When moved by respect for the law, one is concerned with the "universal conformity of [one's] action to law as such." [ $\mathrm{Gl} \mathrm{402]} \mathrm{That} \mathrm{is,} \mathrm{one} \mathrm{wants} \mathrm{one's} \mathrm{action} \mathrm{to} \mathrm{be}$ supported by reasons that are necessary and universally valid (unconditionally valid), and thus sufficient to justify the action fully to anyone. The following would seem to be a principle that expresses the practical implications of these concepts, and as such a candidate for the "supreme principle of morality":

P: Let your reasons for performing an action at the same time suffice to justify your action fully to anyone no matter how situated (give anyone reason to accept what you do).

It is a plausible expression of the requirement that the agent's maxim have the "form of a practical law" (meet the formal criteria of necessity and universality implied by the concept of a practical law), and one who acts from this principle would be realizing the ideals central to the concept of morality. The principle that Kant in fact states is:

FUL: Act only on a maxim which you can at the same time will should hold as a universal law.

Thus, Kant must take the idea of acting from maxims that you could act on while willing that everyone act on them to be equivalent to, or to express, the idea of acting from reasons that are necessary and universally valid. The argument needs supplementation to see why the idea of necessity and universal validity gets cashed out in terms of universalisability. If these principles are equivalent, it is because the Formula of Universal Law provides a procedure for determining whether one's reasons are unconditionally valid. As I interpret it, the key idea is that of reasons sufficient to justify one's action fully to anyone. Since this ideal is quite abstract, we need a way to determine when a maxim satisfies it. This must be the intent of the Formula of Universal Law: asking whether your maxim is one you can at the same time will as a universal law should be construed as the way of determining whether you are acting from reasons that anyone can accept. ${ }^{17}$

\section{Why Moral Principles Must Originate in Reason}

Early in Groundwork, II, Kant stresses at several points that moral principles must originate in reason a priori, and at least two of these 
passages are preparatory to another derivation of the Formula of Universal Law. ${ }^{18}$ It is evident that Kant now seeks a deeper grounding for the concept of morality articulated thus far, by connecting it directly with the nature of practical reason. Why? His primary motivation must be that a grounding of this sort is needed to explain and to preserve the necessity and universality which have emerged as definitive of moral reasons in ordinary thought. If substantive moral reasons do have the unconditional validity that we take them to have, they must come from a principle that originates in reason a priori, since only reason yields principles that apply in this way. A theory that seeks the origin of moral principles elsewhere, such as an empiricist theory, cannot account for their standing as practical laws. Thus, Kant's insistence on the importance of deriving moral principles from reason is in part a rejection of alternative accounts as inadequate, in being unable to ground what he has identified as the features essential to our concept of morality.

To get clear about the problem that Kant is addressing, we ought to note that the first section of the Groundwork simply assumes the ordinary concept of morality, and that Kant thinks that mere clarification of what this concept implies leaves open the possibility that it involves a kind of delusion, or is an empty idea. ${ }^{19}$ Perhaps the considerations that we recognize as moral do not really have the authority that we accord them. We may take certain substantive principles such as truth-telling, refraining from manipulation and coercion of others, helping others, etc, when properly applied, to yield unconditional reasons for acting. But our taking them in this way may reflect nothing more than a process of social conditioning for which no further justification can be given. Or the validity of these principles may depend on desires that one could lack, so that an agent without these desires could claim exemption from the principle. Perhaps there are no unconditional reasons for acting, and the concept of morality, defined as the set of such reasons (or the set of practical laws), while perfectly coherent, is empty and contains nothing. At issue here for Kant is whether there is such a thing as "morality" in the sense of that term implicit in ordinary practice. If morality is what it claims to be, it consists of practical laws; but principles with the character of law must originate in reason.

Kant's account is not directed towards individuals who claim that the authority of moral concerns is illusory, but rather toward those whose understanding of morality threatens to make it an illusion, or to undermine its central features. ${ }^{20}$ These include both agents whose moral practice implicitly fails to acknowledge that moral principles have the status of law, and theorists whose account of morality is unable to explain how moral conclusions can have this status. Regarding the first, one of the major obstacles 
to good conduct in Kant's eyes is not the explicit denial of moral claims, but the tendency to exempt oneself from moral requirements through various forms of rationalization. ${ }^{21}$ We often weaken principles we otherwise accept by making exceptions for ourselves, or by interpreting them so as not apply to the situation in which one is acting. This is to act as though the claims of self-interest are on a par with, or even limit, moral claims, and is equivalent in practice to denying that moral requirements have the status of law. What is needed to counter this tendency is an unambiguous recognition of the authority of moral claims and a story that explains where it comes from. In this respect, moral theory plays a particular practical role for Kant: a proper understanding of the nature and status of moral claims is integral to producing the moral disposition.

Second, Kant's insistence on deriving morality from reason is a rejection of influential empiricist theories that ground moral obligation in empirical facts about human beings, including both psychological facts and facts about the needs of human society and the structure of social interaction. The empiricist may assume some principles of prudential rationality; but he will avoid a priori principles or normative standards whose motivation cannot be supplied by desires and behavioural tendencies people are generally observed to have. Kant's general criticism is that by deriving moral principles from empirically given desires, such theories are unable to ground the notion of a practical law. If the validity of a principle depends on the presence of a desire or interest that one may lack, then there may be agents without that motive, to whom the principle would not apply. Such an agent could only be subject to criticism for lacking the motive which the principle presupposes. But that is to depart from the empiricist viewpoint, by introducing an $a$ priori normative standard to which an individual's desires ought to conform.

Kant wishes to provide an understanding of moral requirements that supports their unconditional validity, and his alternative to empiricism is to derive the moral law from a conception of practical reason which is given $a$ priori. Since Kant is concerned both with content and validity, he must first give a characterization of rational agency that yields this principle and, in addition, guides its application. ${ }^{22}$ The best way to understand the connection is to say that the principle as stated expresses the conception of rational agency. This is to say that it is a principle of choice that an agent defined by that conception of rational agency would choose as his fundamental maxim, in which his practical rationality is most fully realized. Second, Kant must establish the validity of the principle for us by showing that we are rational beings in the required sense, or have reason to view ourselves in that 
way. Though this involves a separate and further step, which is not without its complications, it must to some extent depend on how the first step is carried out. Much of the issue of validity hinges on showing that the principle does express the conception of rational agency, or is the appropriate principle for a being with this nature to act on.

\section{Kant's Conception of Practical Rationality}

At the core of Kant's conception of rational agency is the idea that rational action is guided by considerations that the agent takes to provide justifications for acting in a certain way. We find this view in the following well-known and very important passage:

Everything in nature works in accordance with laws. Only a rational being has the power to act according to the conception of laws, i.e., according to principles. This capacity is will [Wille]. Since reason is required for the derivation of actions from laws, will is nothing else than practical reason . . . the will is a faculty of choosing only that which reason, independently of inclination, recognizes as practically necessary, i.e., as good [ $\mathrm{Gl} \mathrm{412.]}$

The features of rationality cited are quite general, in that in addition to action, they apply to the formation of belief, the carrying out of a proof, anc so on. Rational agency is defined here as the capacity to guide one's actions by normative standards that are generally applicable, such that one's understanding, acceptance and application of these standards to one's circumstances of action figure in the origination of actions. This section will take up the most significant assertions made in the passage, which amount to an ideal of practical rationality. (1) First, it makes claims about the way in which rational conduct originates in the conscious activity of the agent. (2) In addition, it proposes a distinctive view about the nature of practical reasoning and the structure of justification, in which general normative principles play a central role. (3) What emerges is that for Kant, practical reason is in the business of evaluation and justifiction, and that its essential role is to produce judgments about the goodness of actions. Rational conduct is motivated by the recognition of an action as good in some respect, where the goodness of the action consists in the fact that it follows from a general normative principle, or is justified by reasons whose force can be recognized by others. This will be a property of anything we can recognize as a choice.

First, regarding the origin of actions, Thomas Nagel interprets the passage as pointing out that rational action requires a certain form of explanation. He writes: 
Kant observed that rational motivation is unique among systems of causation because any explanation of action in terms of the theory refers essentially to the application of its principles by individuals to themselves in the determination of their actions. ${ }^{23}$

An agent's understanding of principles and reasons, and the resulting evaluative judgments, are the determining features of the causal process by which an action originates, and this must be reflected in any appropriate explanation of why the action occurred. ${ }^{24}$

To see how Kant understands the structure of practical reasoning, we should unpack his remarks that rational agency involves the ability to act "according to the conception of laws, i.e., according to principles." Kant is viewing practical rationality as the capacity to act from "objective practical principles." 25 These are normative principles, general in form, which state how an agent ought to act in a specified kind of situation. ${ }^{26}$ As normative, they correct against distortions in one's judgment about how to act that come from inclinations, or other subjective factors such as lack of information, limited foresight, and so on. Their objectivity consists in the fact that they yield results valid for anyone, and this will have two sides. When properly applied to a situation, they will yield a conclusion about action that will have motivating force for anyone in that situation. In addition, the force which these conclusions have for the agent (in the relevant situation) can be understood by anyone, including by agents not in the relevant situation, for whom they are not reasons to act. ${ }^{27}$ It is important to note that under objective practical principles Kant includes both principles that are conditionally valid as well as those that are unconditionally valid-in other words hypothetical as well as categorical imperatives. ${ }^{28} \mathrm{~A}$ principle may make claims about how one ought to act given the fact that one desires certain ends. It would be objective because it states how anyone with certain desires has (some kind of) reason to act in the kind of situation covered. Properly applied, it will yield conclusions about action that have force for anyone in that situation with the relevant desires; and the force of these conclusions can be understood by anyone, including those for whom they are not reasons to act (because they are not in that situation, because they lack or even disapprove of the assumed desires, etc.). In short, an objective practical principle translates facts about one's situation, and possibly one's ends and desires, into conclusions about how to act whose force can be understood by anyone.

By conceiving of practical reason, or will, as the ability to derive actions from principles, Kant suggests a model in which one arrives at a maxim or course of action by determining whether it is the correct instantiation 
of a normative principle judged to cover the situation in question. Deliberation proceeds by finding a principle covering the circumstances, and then determining what it requires in that situation. This process is open-ended in that the more general principles themselves may be evaluated by the same pattern of reasoning until one reaches an ultimate principle, which neither needs nor is susceptible to further evaluation. Though somewhat awkward as a picture of decision making, this conception does establish a plausible pattern for evaluating proposed actions: an intention already formulated can be assessed by seeing if it is the correct application of a general principle with justifying force for that kind of situation. Moreover, this is the pattern of reasoning that an agent might engage in when explaining why he did a certain action (either to others, or to himself viewing his action from a detached perspective). ${ }^{29}$

There are several points to note here. The first is that this conception locates choice within a thoroughly normative context, in that it sees it as motivated by what the agent takes to be a reason for acting. In this regard, practical reasoning should not be reduced to a kind of calculation or deduction (as might be suggested by one reading of "deriving actions from principles"). It does not simply select actions by deducing them from habitually followed rules, but is rather the ability to choose an action by seeing that it instantiates a normative principle taken to have justifying force. Practical reason evaluates according to normative principles. Second, since this pattern of reasoning may be carried out at higher and higher levels, the structure of practical reasoning leaves room for and creates a push towards ultimate principles that are a source of final reasons. This provides one ground for reading into the text the assumption that rational conduct is guided by some high level principles or ends. A rational agent will have a set of priorities and final ends that provide reasons for action in specific situations, as well as setting limits on the actions there are reasons to perform.

Third, because of their objectivity, the principles that figure in practical reasoning can ground justifications to others; indeed that is the primary impetus of objectivity in the practical sphere. To provide a justification for an action is just to support it with reasons whose force extends beyond the point of view of the agent for whom they are reasons to act. This one does by connecting an action (or maxim) with a general principle stating how anyone ought to act in a certain kind of situation. This provides support for the action which may potentially lead others to accept it (or may lead the agent to accept his own action when viewing it impartially, or from a later point in time). Kant expresses this by saying that objective practical principles issue in judgments of goodness of one sort or another 
(conditional or unconditional). To call an action or an end good in some respect is just to support it with reasons whose force can be understood by anyone-in other words to provide a justification, by bringing it under an appropriate principle. The goodness of a particular action is a function of the objectivity of the grounding normative principles. ${ }^{30}$

Fourth, these points make it plain that one pattern of reasoning serves the dual role of both guiding decision, and of justifying to others. It is distinctive of the Kantian view of rationality that there is a deep connection between motivation and justification: the same considerations by which an agent is motivated also provide some justification of the action to others. The rationality of choice lies in the fact that it is motivated by considerations whose force can be understood by anyone. In this respect it is built into the concept of a rational choice that it proceeds from the recognition of justifying reasons that can be stated in general form, or from judgments of goodness, and that these supply its motivation. It is in this sense that practical reason, as conceived by Kant, is essentially in the business of evaluation and justification.

To make this discussion less schematic and abstract, it may help to give some examples of principles from which an agent might act, which might figure in practical reasoning. Such principles might be formal, such as Kant's Hypothetical Imperative, or the standard principles of rational choice. But of greater interest are agents' substantive principles, which they take to state good ways of acting (to be objectively valid). These are principles accepted by an agent which are sources of reasons for the agent in particular situations, and which they might cite to others to justify their actions. Here some categories are needed, through their boundaries must remain approximate and inexact. One might first distinguish principles taken to represent objective, desire-independent values, e.g.:

(a) One should always be truthful, except when dishonesty is needed to resist manipulation or coercion against yourself, or harm to another.

(b) When someone on the street asks you for money, give what you can if they appear truly destitute, but not otherwise.

(c) Never respond to those Publisher's Clearing House mass mailings (since that simply plays into the crass commercialism of our society which ought to be resisted).

Some desire-dependent principles state generally reliable ways of satisfying desires that most people have, or might come to have at some point. These fit what Kant terms "counsels of prudence": 
(d) Honesty is the best policy.

(e) Always respond to those Publishers Clearing House mass mailings; it takes little time and energy to fill out the form and you never know when you might win.

(f) Never give a sucker a break. (Since a sucker is an easy target, that is a generally effective way of furthering your ends.)

Other desire-dependent principles depend more openly on desires peculiar to specific individuals:

(g) When you see someone who is about to ask you for money, cross the street right away (so that you won't feel pressured to give, can avoid a disgusting sight).

(h) What is important above all else is leading a life of luxury and ease.

A principle that an agent accepts as objectively valid may or may not have the status that he or she takes it to have. A principle such as (c) might be viewed by the agent as unconditonally valid; but it might turn out to be no more than an expression of a value or a desire peculiar to the agent not universally supportable, and thus only conditionally valid. A principle such as (d) might simply be false if, in the circumstances intended by the agent, honesty is not the best way of furthering one's interests. (In that case, as stated, it would only be a subjective principle-a principle from which the agent acts, through not objectively valid.)

The last group do not appear to have much normative force; they seem more like characteristic principles of specific individuals, rather than principles that make claims about how people in general ought to act. But they may be viewed as (elliptical) hypothetical imperatives directed to individuals with certain desires (those undone by the sight of destitute people, or those who detest hard work, uncertainty and anxiety, etc.). If they in fact stated effective means of satisfying certain desires, and thus conformed to the Hypothetical Imperative, they would be objective practical principles. And they might have derivative normative force if they were instantiations for an individual of a higher level principle taken to have final justifying force, which (following Kant) could be termed the Principle of Happiness:

(PH) Act so as to maximize over time the satisfaction of your own desires, whatever they may be.

I include these latter examples to show that the justifying force of some conditional principles might be quite minimal. The reasons derived from a principle may at most render an action intelligible, and fall far short of giving 
others reason to accept or approve of the actions that fall under it. In cases of this sort, objectivity may amount to nothing more than an appropriate connection between an action and given desires and aims of an individual in a particular situation, that anyone can discern. For example, if your guiding aim is to lead a life of luxury and ease, that will be a source of reasons for you in specific circumstances, even if not good reasons. I, who favor penury and struggle (or perhaps as someone in great need), can appreciate that you have a reason not to be generous in some situation given this general aim, even though I may reject the aim from which these reasons get their force, and the actions to which they lead.

This passage stresses the ability to act from normative principles, but that does not exhaust Kant's understanding of practical rationality. Elsewhere in the Groundwork Kant articulates other aspects of his conception of rational agency, which appear to be implicit in the fundamental notion. ${ }^{31}$ In a second important passage preceding the introduction of the Formula of Humanity, Kant writes:

The will is thought of as a faculty determining itself to action in accordance with the representation of certain laws, and such a faculty can only be found in rational beings. Now what serves the will as the objective ground of its determination is an end .... [G] 427]

What this passage and the ensuing discussion add is that rational agency also involves the ability to set and pursue ends. In light of the preceding account of practical reason, this capacity must be understood as a responsiveness to objective value. The rational agent does not simply act so as to satisfy given preferences, but adopts ends (including objects of its preferences) for reasons which have force from the point of view of others. Thus, it involves the capacity to select ends viewed as good or worthy of choice, or to recognize or place a value on a state of affairs. To say that an end is adopted by being regarded as good or of value implies several things. An agent adopts an end because it instantiates a higher level end or value taken to be good per se (in which case the value of the end is derivative), or because it is taken to be good in itself. Once adopted, the end becomes a source of reasons for the agent which give it a degree of priority relative to one's other desires and ends. These reasons are desire independent to the extent that their force can remain constant despite fluctuations in the strengths of one's desires, and can override desires that may interfere with the pursuit of the end. They are sufficient both to initiate courses of action, as well as restrict other actions and pursuits that are inconsistent with an end. In addition, the agent's reasons for adopting an end should allow other agents to see why he takes it to be worthy of choice. Presumably its value to 
the agent can be recognized by others, and gives them a reason to respect the agent's pursuit of the end (though one that can be overriden in various ways). ${ }^{32}$

\section{Practical Reason and Complete Justification}

To understand how Kant locates the origin of moral principles in reason, we must consider how the above conception of practical rationality leads to a statement of the moral law. The view that I want to attribute to Kant is that the idea of a practical law is implicit in the nature of practical reason as a faculty that evaluates according to normative principles and constructs justifications. If so, the arguments of Groundwork I and II discussed earlier would give Kant what he needs. Recall his view that the idea of a practical law, or equivalently, the concept of a categorical imperative, yields a formulation of the only principle that can be a categorical imperative-that is, the idea of a practical law yields the Categorical Imperative. ${ }^{33}$ If this argument holds, and if the idea of a practical law may be derived from the nature of practical reason (as understood by Kant), then the Categorical Imperative would have been traced to the nature of practical

reason. What we want to see here is how the Categorical Imperative can be viewed as the principle in which this conception of practical rationality is most fully expressed-say, as the principle by which the business of practical reason is most fully carried out or completed. Roughly, it is because movement towards the unconditional is built into the process of evaluation and justification, and it is by finding justifications that are unconditionally valid that the process is completed. But justifications of this sort require grounding in a practical law. Since the Categorical Imperative states the form that any practical law will have, it is the principle by which the business of practical reason is completed. In this way, the characteristics of moral evaluation are tied to the nature of practical reason, and shown to be expressed in the Categorical Imperative.

To develop this point, let us consider what is needed to arrive at justifications that are complete. The discussion of the last section shows that objective practical principles, and the justifications which they ground, need only be conditionally valid. The objectivity of a practical principle requires only that its application yield conclusions about action that have force for anyone in the relevant situation, and that their force can be understood by anyone. This allows that an objective principle may show that an action is a good thing to do, or that there are reasons to perform it, given certain further conditions (the agent desires certain ends, accepts certain values, etc.). Justifications of this sort are partial or incomplete, and 
the ways in which they are conditioned lay out directions in which development towards completion is possible. Complete justification is achieved by extending the normative force of reasons as far as possible in these directions.

We may distinguish two different dimensions along which justification must move to achieve completion. The first is the direction of finality. You may judge that an action is good as a means to an end, or relative to certain desires. In that case, there is reason to perform the action only if there is reason to pursue the end, or if the desires in question are good ones to act on. Or, you might judge that an action or an end is good in itself, but that there is reason to pursue it only if certain limiting conditions are satisfied. It is good "other things being equal"-i.e., if it is consistent with your other priorities, violates no prior obligations, etc. Such judgments lead one to look for further reasons beyond those initially advanced in support of the action-either to seek reasons for the end, in the first case, or to determine whether the limiting conditions are satisfied, as in the second case. In both cases a search is initiated for final reasons not in need of further support, which either provide positive support for the action, or show that it is fully consistent with other considerations that have priority.

The other direction is towards universal validity. What you take to be a sufficient reason for acting may fall short of giving others reason to accept what you do. You intend to do $\mathrm{X}$ because it promotes a life of luxury and ease, which is for you a final aim of overriding importance. (It will give you happiness, and after all, what else is there?) I can see why $X$ is a good thing for you given your aims, but since I do not place the same value on the aim as you, I am not moved by your explanation. (Besides, $X$ shows a disregard for my person.) Here your justification is shown to be conditional on an assumption that is not universally acceptable; specifically, I have no reason to accept it. Justification is complete in this direction when the objectivity of reasons has been pushed towards universal validity. That is, in addition to leading others to see why you take the action to be a good thing to do, your reasons lead them to see it as good and to accept it. In this case, an agent's reasons for acting are at the same time sufficient to give anyone reason to accept what he does.

One has travelled as far as one can in each direction when one arrives at reasons whose finality is universally valid. Such reasons are necessary, universal and take priority over others; that is, have the status of a practical law. They complete the process of justification in that they are sufficient to justify an action fully to anyone. This represents the most complete exercise of practical rationality, in that the normative features present in any reason 
are found in their most complete form, and the normal function of practical reason is carried out to a maximal degree.

I hope to have shown how, in Kant's view, moral choice builds on and extends a concern for justification and evaluation present in all forms of reasoning and choice. A strength of this interpretation is that it reveals a continuity between moral and non-moral choice that we tend to overlook due to various of Kant's dichotomies. It suggests, for example, that the psychology needed to explain how we can care about and act from the moral law is provided by the capacities constitutive of rational agency. Moral conduct requires no fundamentally different abilities or motives beyond those that go into the reasoned choice of actions and ends in ordinary contexts. What makes this possible, of course, is that Kant's conception of practical rationality already incorporates substantive ideals with a recognizably moral component. But that should not trouble us as long as the ideals are sufficiently fundamental to our way of viewing ourselves. Kant's project, as I have said, is not to derive the moral law from a morally neutral starting point, but to connect it with basic features of reasoning and choice, and to show how deeply embedded the elements of morality are in all forms of deliberation.

This paper has focused on the Formula of Universal Law. Since Kant derives three principal formulations of what he thinks is a single imperative, to complete the account begun here would require showing that the framework which it adopts may be extended to the other formulas and their equivalence. I will conclude with a suggestion about how this may be done, which I can only sketch here. It is that the alternate formulations of the Categorical Imperative express different aspects of a single conception of rational agency, and that we look to the relationships between these aspects of rationality to throw light on the equivalence of the formulas. We have seen that the core notion of practical rationality is the capacity to act from general normative principles which may be used to justify one's actions to others. The Formula of Universal Law may be regarded as the principle by which this capacity is most completely expressed, in that it embodies the ideal of acting from reasons that are unconditionally valid. In representing the general form of a practical law, it states the ideal of complete justification. Rational agency also involves the ability to set and pursue ends, which in this context should be understood as the capacity to adopt ends viewed as good or of value. This aspect of practical rationality is most fully expressed in the Formula of Humanity, which states the requirement of guiding one's conduct by the recognition of an end of absolute value, that conditions the value of any end. Finally, the ideas of freedom and self-determination are 
built into this conception of practical rationality. The actions of a rational agent are self-determined in that they result from the agent's understanding and application to herself of reasons and principles that she accepts. The capacity to be guided by normative considerations makes one free by giving one the ability to choose actions other than those that would result from the balance of existing desires; you can do what you ought to do, regardless of what you desire. This aspect of practical rationality underlies the Formula of Autonomy. That the Formula of Autonomy follows directly from the Formula of Universal Law [G] 431-433] shows that autonomy is the foundation of morality-that moral principles must be such that we can regard ourselves as their authors and subject to them for that reason, and that when we act from the moral law we act with full autonomy. The latter point in particular must rest on the idea that in acting from reasons that are unconditionally valid, one's actions are most completely guided by one's capacity to act from reasons, and thus most completely self-determined. Thus the powers of freedom and self-determination implicit in all rational choice are most fully realized in morally good conduct. Kant thinks that the form of a practical law is identical with the form of volition in general, or the general structure of what it is to act from will. ${ }^{34}$

Here is a way of relating the different formulas by showing that each is the full expression of a different aspect of a single ideal of rational agency. It offers support for the contention that they are just different versions of the same Idea. One of the more remarkable features of Kant's theory is its attempt to demonstrate the deep connections between these ideals, and to weld them together into a single moral conception. ${ }^{35}$

North Carolina State University

Andrews Reath

\section{NOTES}

1. Cf., e.g., Gl 389. References to the Groundwork of the Metaphysic of Morals will be to the pagination in the Prussian Academy edition of Kant's Gesammelte Schriften, and are included in the body of the paper where possible. (Though I prefer Paton's title, the translation used is that of James Ellington.) Citations to other works of Kant give the page in translation, followed by the page in the Prussian Academy edition. The abbreviations and translations used are as follows:

Gl Grounding of the Metaphysics of Morals, tr. James W. Ellington, in Kant's Ethical Philosophy (Indianapolis, IN: Hackett Publishing Company, 1983). 
KpV Critique of Practical Reason, tr. Lewis White Beck (Indianapolis, IN: Bobbs-Merrill, 1956).

$K U$ Critique of Judgment, tr. James Meredith (Oxford: Clarendon Press, 1952).

MdS The Doctrine of Virtue: Part II of the Metaphysic of Morals, tr. Mary J. Gregor (University of Pennsylvania Press, 1964)

Rel Religion Within the Limits of Reason Alone, tr. T. M. Greene and H. H. Hudson (New York: Harper \& Row, 1960)

2. Cf. $G l 412 \mathrm{ff}$ and $426 \mathrm{ff}$, which precede, respectively, the statements of the first two formulations of the Categorical Imperative. In the first Kant writes that "the principles should be derived from the universal concept of a rational being in general, since moral laws should hold for every rational being as such." He then says that to carry this out, he will "present the practical faculty of reason from its universal rules of determination to the point where the concept of duty springs from it." In the second, Kant says that the moral law "must be connected (completely a priori) with the concept of the will of a rational being as such." The discovery of this connection requires a "step into metaphysics" and an investigation into the possibility of reason determining conduct $a$ priori.

3. In the Preface, Kant writes that "the present Groundwork . . . is nothing more than the seeking out and establishment of the supreme principle of morality ...." ( $G l 392)$ The "seeking out" of the supreme principle occupies the first two sections of the Groundwork; their concern is the proper formulation of the moral law (the content) and they leave open the question of its validity. For Kant, the latter is the question of whether the demands contained in our ordinary concept of morality are indeed valid and real: do they really bind us? (For different statements of the question of validity see $G l 426,445$, and especially 449ff: "But why should I subject myself as a rational being ... to this law?" Why must "the universal validity of our maxim as a law be the restricting condition of our action"?) The moral law is not "established" until the third section, when this issue is addressed. My discussion will be limited to the arguments of the first two sections of the Groundwork.

Recent commentators concerned with Kant's derivation of morality from reason have tended to take the validity of the moral law to be the main issue, and have thus focused on the third section, and related arguments in the Critique of Practical Reason. See, e.g., Thomas E. Hill, "Kant's Argument for the Rationality of Moral Conduct," Pacific Philosophical Quarterly 66, nos. 1 \& 2 (Jan/April 1985); Henry E. Allison, "Morality and Freedom: Kant's Reciprocity Thesis," The Philosophical Review 95, no. 3 (July 1986); and Christine M. Korsgaard, "Morality as Freedom" (forthcoming in Kant's Practical Philosophy Reconsidered, the proceedings of the 7th Jerusalem Philosophy Encounter). (But see also her "Kant's Formula of Humanity" (Kant-Studien 77, no. 2, 1986), which includes an account of how the Formula of Humanity is derived from practical reason.) However it is equally important to see how Kant derives the content of the moral law from a conception of practical reason. Indeed, the answer to this question may largely determine how the later issue ought to be treated.

4. "Truth, Invention and the Meaning of Life," in Proceedings of the British Academy, LXII (1976), p. 364n. For a recent discussion and response to Wiggins's critique of this project see David Gauthier, "The Unity of Reason: A Subversive Reinterpretation of Kant,"' in Ethics 96 (October, 1985): 83-86. 
5. See Ethics and the Limits of Philosophy (Cambridge, MA: Harvard University Press, 1985), p. 28. Williams's discussion of Kant by and large assumes that Kant's conception of practical reason is morally neutral; see ch. 4. Gauthier also makes this assumption (see work cited above, p. 84).

6. Here note Kant's distinction between the "predisposition to humanity in man, taken as a living and at the same time a rational being" and the "predisposition to personality in man, taken as a rational and an accountable being." [Rel $21 \mathrm{ff} / \mathbf{2 6 \mathrm { ff }}]$ The former is a conception of instrumental rationality in that it involves, among other things, the ability to set and pursue ends on the basis of their contribution to one's overall happiness, understood to involve the maximally harmonious satisfaction of given desires. The predisposition to personality is the basis of morality, and Kant stresses that it is a "special predisposition" not included in the first. I am indebted to Stephen Engstrom for discussion of this passage and related issues.

7. This point is made by Thomas E. Hill, Jr., "The Hypothetical Imperative," The Philosophical Review 82 (1973): 443, whose account I follow in this paragraph.

8. For textual evidence of this interpretation see $M d S 56 / 395$; while in the Introduction to the Metaphysic of Morals pure practical reason had been described as a "power of principles" [MdS 10/214], here it is called "a power of ends as such." See also the "Conjectural Beginning of Human History" where reason is viewed as the power to set ends beyond those given by instinct and inclination (and which can create new desires), as well as the power to make provision for future ends one may have; in On History, ed. Lewis White Beck (Indianapolis, IN: Bobbs-Merrill, 1975), $55 / 111-59 / 115$. Though the uses of reason referred to here are not "pure," it is worth noting its independence from inclination, as well as the continuity between these uses of reason and the form of moral reasoning referred to at the end of the passage.

9. Cf. Gl 393-94, 397-401.

10. There is some ambiguity throughout the Groundwork as to whether Kant's primary focus is moral worth or moral rightness. I take it to be the latter, despite Kant's constant attention to acting from the motive of duty. Thus, I view the discussion of moral worth in the First Section as a step on the way towards a statement of the principle of right conduct. One aspect of Kant's theory that may promote this ambiguity is that the principle of right, in addition to outlining a procedure for evaluating actions, also determines the weight that moral reasons have relative to other kinds of reasons. Since moral worth is achieved by recognizing the priority of moral reasons and being motivated accordingly, considerations of right conduct lead naturally to considerations of moral worth.

11. In other words, moral deliberation will generally be about actions under descriptions, in which agents bring certain kinds of substantive considerations to bear on a situation (honesty, fairness, etc.). The Categorical Imperative is the schematic rendering of the reasoning implicitly used, which states its underlying form.

12. As he says, the "mere concept of a categorical imperative ... [may] supply us with the formula containing the proposition that can alone be a categorical imperative"; and that "if I think of a categorical imperative, I know immediately what it contains." [ $\mathrm{Gl} 420]$ I comment on this argument in n33 below.

13. Here see Kant's "third proposition" [ $G l 400]$ : "Duty is the necessity of an action executed from respect for the law." While much is packed into this statement, I 
take the main idea to be that the concept of duty represents the special weight that those actions have which are done from the recognition that they are morally right. Thus Kant focuses on the "necessity" of actions selected by the balance of moral reasons - the fact that they ought to be done no matter what one desires most strongly, no matter how people tend to act in such situations, whether or not the action is sanctioned by existing social practices, etc.

In this passage Kant focuses on the motivational state which is the appropriate response to (full recognition of) moral reasons as a way of bringing out their defining features. But he could also have looked simply at what is implied by the concept of a duty, insofar as the necessity and universality of particular duties are a part of their content. This Kant does, I believe, in the Preface [389], when he says that "the common idea of duty" must carry with it "absolute necessity." Kant's preference for the "subjective route" (through attention to the characteristic motivational attitude) might be explained by the fact that much of the First Section works through an appeal to moral experience. The defining features of morality are not just described; Kant wishes to elicit through examples a recognition of them that has motivating force.

14. That is, "conditions only contingently related to the will," or "contingent subjective conditions that differentiate one rational being from another." See $K p V$ 18f./20f.

15. I am calling necessity and absolute priority what I take to be slightly different features contained in Kant's usage of "necessity" [Notwendigkeit]. For brevity, I will generally refer (as he does) simply to the necessity and universality of moral reasons, or to their unconditional validity.

16. Any practical principle is going to be universal in that it applies to anyone who satisfies its conditions. Universality in this sense is, of course, not sufficient to make a practical principle a law. (In fact, this is better called its "generality".) Here it is worth noting that the distinction between principles and ends is not important in the derivation of a practical law. To show that there is an end which has an intrinsic and absolute value (i.e., one which takes priority over and limits other forms of value) is to have established the existence of a practical law. This, of course, is what Kant does in his derivation of the Formula of Humanity, and it explains in part why the first two formulas are equivalent. What is crucial to the concept of a practical law is the notion of absolute value, and this can be expressed equally in a principle that yields determinate prescriptions with overriding weight, or in the idea of an end of absolute value.

17. Here I suggest that we need to complete Kant's argument by showing how the idea of unconditional validity leads to the universality tests that he adopts in various texts. This involves determining the implications of the Moral Law when applied to the general circumstances of human life. One would proceed by showing how universality tests might be derivable from the idea of reasons that justify one's actions fully to anyone in conjunction with general facts about human beings and human social existence. Attention to general human needs, to the fact that we live in the society of others and are dependent on certain forms of social cooperation, to the ways in which social practices operate and to social interaction in general, and so on, might make it plain why the Formula of Universal Law is required by the idea of unconditional validity. For example, facts about how social practices deliver the benefits that they do, and about the degree of adherence that is required for them to operate, 
might explain where the Contradiction in Conception test comes from, or why fairness is required by full justifiability to anyone. In addition, the primary concepts may have implications for the construction of universality tests; we want forms of reasoning that are aimed at uncovering reasons that anyone can accept.

18. Cf. $G l$ 408-09, 411-12, 425-27; see also 389-90.

19. Kant raises the possibility that the concept of morality might lack objective reality, though not always in the same sense, at $G l 402,405,407-08,421,425$, and 445. He writes that "mere conformity to law as such" must be the principle of the will "if duty is not to be an empty delusion [ein leerer Wahn] and a chimerical idea [chimärischer Begriff] [402]; and that the objective of the step into practical philosophy in the Second Section is to "obtain information and clear instruction regarding the source of its own principle and the correct determination of this principle in its opposition to maxims based on need and inclination, so that reason ... may avoid the risk of losing all genuine moral principles through the ambiguity into which it easily falls." [405] Here his point is that our concept of duty requires that we treat moral considerations as unconditionally valid, which presupposes that they originate in reason a priori. (Somewhat optimistically he thinks that clarity about the fact that moral requirements originate in reason is enough to get us to accept the practical impact of their having the status of law.) See in particular 408: “ . . . unless we want to deny to the concept of morality all truth and reference to a possible object, we cannot but admit that the moral law . . . [holds] for all rational beings generally, and that it must be valid not merely under coningent conditions and with exceptions, but must be absolutely necessary."

It seems that different questions about the "reality" of the moral law are left open at different stages of the argument, and that both Groundwork II and III address a question of whether the moral law might only be an empty idea. The First Section articulates some of the essential features of moral claims, as we understand them; but they would still be illusory unless they originate in reason. The Second Section is a more detailed analysis of the concept of morality that shows that duties must be expressed in categorical imperatives $[G l 425]$ and that the autonomy of the will must be the foundation of morality [ $\mathrm{Gl} 445$ ], and gives the proper formulation of the moral law. It addresses the issue left open by the First Section by tracing the Categorical Imperative to the nature of practical reason [Gl 412-16, 420ff], but stops short of establishing the validity of its requirements for us. [ $G l 425,440-45]$ That requires a "synthetical use" of reason, presumbly one which shows that we have the rational nature presupposed by the moral law, and is the subject of the Third Section.

20. Here I am in agreement with Thomas Hill, who argues that Kant is not addressing the moral skeptic, but rather an audience with ordinary moral concerns "whose moral commitment is liable to be called into question by philosophical accounts of practical reason which imply that morality could not be grounded in reason." See "Kant on the Rationality of Moral Conduct," Pacific Philosophical Quarterly 66 (1985): 4.

I might add that, if Kant is not addressing an audience which is initially indifferent to moral concerns, then his conception of reason need not be devoid of substantive ideas (of the person, or of agency). Indeed a theory that does proceed from such a starting point is likely to obscure the way of viewing persons to which Kant thinks that moral thought provides access. 
21. This is the "natural dialectic" within practical reason which Kant describes as "a propensity to quibble with these strict laws of duty, to throw doubt upon their validity or at least upon their purity and strictness, and to make them, where possible, more compatible with our wishes and inclinations . . . " [ $[\mathrm{Gl} 405$; see also $\mathrm{Gl}$ 424f. and $K p V 16 / 16$.]

22. Ideally the notion of rational agency will be a foundation that really supports and animates the structure. That is, it does not just yield the basic principle; it will also figure in the application of the principle to concrete situation, and thus hold a substantive role in the moral conception which it grounds. The conception of rational agency should be an ideal that we can plausibly apply to ourselves and others in normal social interactions, which will have implications for how individuals are appropriately treated. (Certain ways of treating others recognize their rationality in the relevant sense, and an understanding of the conception of rational agency should guide one's judgments, and make one better at applying the principle.)

23. The Possibility of Altruism (Princeton, NJ: Princeton University Press, 1970, 1978), p. 22. See also Thomas E. Hill's discussion in, "Kant's Argument for the Rationality of Moral Conduct," pp. 8-9. He notes that a rational agent is able

to make things happen in such a way that the appropriate explanation is reference to the principles, laws, or reasons on which the person acted. Principles, even laws, enter into the explanation of why a rational agaent did something ... as the agent's guiding "ideas" or rationale, not as empirically observable regularities among types of events.

Cf. also H. J. Paton, in The Categorical Imperative (University of Pennsylvania Press, 1971), pp. 81-82.

24. Of course, other forms of explanation are possible, but they no longer view the causality as rational. Many people would agree that such explanations are incomplete because they ignore aspects of an agent's perspective on his or her conduct, which are central to the agent's self-conception. For a discussion of this point in a different context, see H. L. A. Hart on the "internal aspect of rules," and his argument that certain positivist accounts of law fail by ignoring it: The Concept of Law (Oxford: Oxford University Press, 1972) pp. 55-57, 81-82, 86-88, 99-102. See also Nagel's recent discussion in The View From Nowhere (Oxford: Oxford University Press, 1986) pp. 141-43, 150-52.

25. The text is made somehat unclear by a terminological slide from "objective laws" to "objective principles," or "imperatives." He may appear to define rational agency as the capacity to act from practical laws (i.e., categorical imperatives), but the context makes it clear that he intends the weaker definition as the capacity to act from objective practical principles, which, as I explain, include both hypothetical and categorical imperatives. (The first interpretation would make rational agency a moral capacity by definition.) A similar ambiguity is seen in the definition of practical principles early in the second Critique. (KpV 17ff/19ff) Here Kant begins by distinguishing practical laws from maxims, or subjective principles of action-i.e., those actually adopted by an agent. But it becomes clear that the distinction in which he is interested is between subjective principles of action and objective practical principles valid for any rational being, including both practical laws and valid prudential precepts.

How Kant distinguishes subjective and objective principles has been the source of a certain amount of confusion. See, e.g., Bruno Bauch, Immanuel Kant (Berlin und Leipzig: De Gruyter, 1921), pp. 304-08. 
26. Thus, a practical principle does not simply state a characteristic way of acting, or a rule to which an agent's behaviour conforms. That would assimiliate practical laws to the model of laws of nature. Rational conduct presupposes not just that behaviour conform to a principle, but that it be guided by an awareness or acceptance of that principle. It provides a description of the behaviour that the agent would apply to himself, which could be used to state his intentions, or would be accepted as relevant to evaluation of the action.

27. Here I draw on Nagel's discussions of objectivity; see The View From Nowhere, pp. 152-54.

28. Hypothetical Imperatives are objectively valid, in that they embody claims about the means needed to achieve a given end that are true for anyone. However they give reasons conditionally, in that they lead to determinate prescriptions only in conjunction with facts about an individual's desires. Thus, hypothetical imperatives are practical principles that are objectively, but conditionally valid, stated in imperative form for finite rational beings. For discussion, see Thomas E. Hill, "The Hypothetical Imperative," The Philosophical Review 82 (1973): 440 ff; and Henry E. Allison, "Morality and Freedom: Kant's Reciprocity Thesis," The Philosophical Review 95 (1986): 399-400.

29. It is implausible to think that an agent must consciously go through such a process in deciding how to act, but that need not be Kant's view. Rather, a structure of this sort may be implicit in practical reasoning, and presupposed by what agents offer as justifications for their actions. Thus I would argue that Kant views a maxim (first person principle stating an agent's underlying intention) as providing a prima facie justification for an action. But since it must instantiate a general principle stating how anyone ought to act in order to function in this way, some such principle is presupposed in the background. It is enough for Kant's purposes that this structure be brought into play in assessing proposed alternatives; it need not describe how an agent arrives at these alternatives.

30. Thus Kant writes:

That is practically good which determines the will by means of representations of reason and hence not by subjective causes, but, objectively, i.e., on grounds valid for every rational being as such. [Gl 413]

What is good is also "practically necessary"-an action supported by an oughtjudgment of some kind. Cf. Gl 412. See also $K p V 60 \mathrm{ff} / 58 \mathrm{ff}$, esp. 62/60: "What we call good must be, in the judgment of every reasonabale man, an object of the faculty of desire ... ;" and $K U \S 4$.

31. See also $G l$ 448:

Now we cannot possibly think of a reason that consciously lets itself be directed from outside as regards its judgments; for in that case the subject would ascribe the determination of his faculty of judgment, not to his reason, but to an impulse. Reason must regard itself as the author of its principles independent of foreign influences.

Here Kant views rationality as a power of self-determination.

32. In support of this interpretation of the attitude of rational agents towards their ends, note that when Kant discusses the adoption of ends he standardly refers to their value or worth [Wert]. He asks whether it is conditional, relative or absolute [ $G / 428 \mathrm{ff}$ ]; he also refers to the question of whether an end is "reasonable and good" and comments on the importance of "judgments regarding the worth of things which might be chosen as ends." [ $G / 415]$ 
For a more complete discussion of this passage than I am able to provide here, see Christine Korsgaard, "Kant's Formula of Humanity," secs. III-V. One of her aims is to clarify how the traits of rational nature (what she terms its power to "confer value") are the source of its unconditional value. Briefly, the argument (as I understand it) is that rational nature is an end of absolute value because it is a precondition of the existence of any ends. Without the ability to pursue ends for reasons and to confer value on the objects of our desires, there could be no valuable ends. Since rational nature is an end of absolute value, it imposes limiting conditions on choice which must always be respected.

33. This argument would appear to begin by defining a categorical imperative as one that states an unconditionally valid requirement on action. Kant writes:

For since, besides the law, the imperative contains only the necessity that the maxim should conform with this law, while the law contains no condition to restrict it, there remains nothing but the universality of law as such with which the maxim of the action should conform. This conformity alone is represented as necessary by the imperative. [ $G l$ 420-21]

I gloss this passage as follows. A categorical imperative will contain a law-that is, a substantive requirement on action that applies without restriction to anyone. In addition, it specifies the priority which this requirement has with respect to one's desires and ends: it states the necessity of acting consistently with this particular law. The Categorical Imperative-as the principle underlying all particular categorical imperatives, which states their general form - can only contain the necessity for conformity to law as such. It states the requirement of acting from reasons that satisfy the criteria of necessity and universality, or are sufficient to justify one's action fully to anyone. So the supreme practical law says: act from maxims that have the form of law.

34. In these remarks about autonomy I simply summarize the directions that Kant's thought takes. I intend to examine them more critically in another paper.

35. I received support for this paper from a National Endowment for the Humanities Summer Stipend (\# FT-29143-87). I am also indebted to Stephen Engstrom, Hannah Ginsberg, and Christine Korsgaard for discussion of various topics within Kant's philosophy during the writing of this paper, which have no doubt influenced its present form. 